International Journal of Engineering, Science and Technology

Vol. 1, No. 1, 2009, pp. 172-189
INTERNATIONAL

JOURNAL OF

ENGINEERING,

SCIENCE AND

TECHNOLOGY

www.ijest-ng.com

(C) 2009 MultiCraft Limited. All rights reserved

\title{
Bioeconomic analysis of Maryland's Chesapeake Bay oyster fishery with reference to the optimal utilization and management of the resource
}

\author{
T. K. Kar ${ }^{\mathrm{a}^{*}}$ and Kunal Chakraborty ${ }^{\mathrm{b}}$ \\ ${ }^{a}$ Department of Mathematics, Bengal Engineering and Science University, Shibpur, Howrah-711103 \\ ${ }^{b}$ Department of Mathematics, MCKV Institute of Engineering, 243 G.T.Road (N), Liluah, Howrah-711204 \\ E-mails:(tkar1117@gmail.com (T.K.Kar), ${ }^{*}$ Corresponding author); kc_mckv@yahoo.co.in (Kunal Chakraborty)
}

\begin{abstract}
The present paper deals with the surplus production models of Verhulst-Schaefer and Gompertz-Fox that are applied to the Maryland's Chesapeake Bay oyster fishery to investigate the sustainability properties of the stock and management of the fishery. The basic objective of this paper is to illustrate the way in which long run sustainability can achieve an optimum exploitation of the fishery. For this purpose, conventional economic model is used along with biological population growth model to develop a bio-economic model. The parameters of the bioeconomic model are estimated using empirical data of catch, effort and price of the Maryland's Chesapeake Bay oyster fishery. Standard reference points are analyzed and tax policies are introduced to achieve the standard reference points. In order to achieve maximum level of profit from the fishery optimal steady state solutions i.e., optimum levels of stock, harvest and effort are determined.
\end{abstract}

Keywords: Bioeconomics, fisheries management, reference points, price function, tax

\section{Introduction}

The management of renewable resources has long been practised using the MSY (maximum sustainable yield) concept whose primary objective is to avoid over exploitation. The MSY is a simple way to manage resources taking into consideration that overexploitation of resources lead to a loss in productivity. Therefore, our aim is to determine how much we can harvest so that long run sustainability of the population can be achieved. On the biological side, the word 'yield' may often appear ambiguous, especially in cases in which several ecologically independent species are harvested simultaneously. In such cases, maximization is simply impossible. Therefore, some method of forming a weighted sum must be employed. The outcome will then depend on the weighed system which includes suitable environment, growth of the population, number of species, economic value etc. The maximum yield concept must clearly be modified if these complications are to be incorporated. The word 'sustainable' is equally problematic biologically since unpredictable and large variations are observed in case of marine fish populations. Consequently, the term 'sustainable' is feasible when population levels are high but the population is not sustained at lower population levels. The main problem of the MSY is economic irrelevance. It is so since it takes into consideration the benefits of resource exploitation, but completely disregards the cost of resource exploitation. For example, it ignores the fact that if a species is harvested to such an extent that its population decreases to a certain level, then the cost of harvesting can become high because finding the desirable resource becomes more time consuming. This will lead to a situation where the cost of harvesting will be higher than the benefit.

To overcome those inadequacies of MSY, it is observed that many researchers in recent time have tried to replace the concept by OSY (optimum sustainable yield) which is based on the standard cost benefit criterion used to maximize the revenues. Nowadays it is also observed that maximum economic yield (MEY) is globally accepted as fishery management tool. Scientists and researchers agreed that maximum economic yield (MEY) can be considered as a new strategy based on long term approach to solve the problem of over exploitation of fisheries and enhance the revenue of the fishery through implementing the sustainable properties of the fisheries. 
The mathematical and bio-economic theories concerning renewable resources for harvesting have been systematically developed by Clark $(1985,1990)$ in his two books. He discussed the management of biological population from an analytical point of view. Chaudhuri and Johnson (1990) developed a bioeconomic model of a single-species fishery by using a catch-rate function which is more realistic in comparison to the CUPE usually adopted in the literature. In their model, imposition of a suitable tax on the landed biomass was taken as a governing instrument to regulate exploitation and the optimal harvest policy was discussed by using control theory. Saha Ray and Chaudhuri (1996) studied exploitation of a two- species prey-predator fishery considering effects of environmental perturbations on the populations. Loehle (2006) summarized the comparison between control theory assumptions and the real ecological systems to which the method was applied. He developed a fishery's example to illustrate some improvements to the application of this technique. Kar and Chaudhuri (2004) discussed a bioeconomic model of two-prey and onepredator fishery with linear functional response. Models on combined harvesting of two-species prey-predator fishery have been discussed by Kar et al. (2006).

Kizner (1997) focused on the stability analysis of a certain class of catch-effort controlled discrete stock-production models for optimal management of exploited populations, which were used as official methods for Cape hake assessments in the International Commission for the Southeast Atlantic Fishery (ICSEAF) during 1988 -1990. The empirical analysis of the North Sea herring fishery was discussed by Bjorndal (1987) by incorporating fishery production function. He defined an intertemporal profit function by introducing stock dynamics and the concept of a sole resource manager. Kronbak (2005) set up a dynamic open-access model of a single industry exploiting a single resource stock. He applied the model empirically to describe the dynamics of the eastern Baltic Sea cod fishery. Mikkelsen (2007) investigated aquaculture externalities on fisheries, affecting either habitat, wild fish stock genetics, or fishing efficiency under open-access and rent maximizing fisheries. He considered Verhulst-Schaefer model of fish population-dynamics and production, coupled with a simple aquaculture production model.

Kar and Matsuda (2008) examined the impact of the creation of marine protected areas (MPAs), from both economic and biological perspectives. Particularly, they examined the effects of protected patches and harvesting on resource populations. They discussed the impacts of MPAs on resource populations without applying the reference points of a fishery. Also, they did not have any empirical evidence in support of their conclusions. Kar and Chakraborty (2009) considered a prey-predator fishery model with prey dispersal in a two-patch environment, one of which is a free fishing zone and other is protected zone. In their study though they have considered economic rents (fishery rent and ecotourism rent) in a fishery but the tax policies were not discussed. Kar and Chaudhuri (2003) studied a dynamic reaction model, in which prey species are harvested in the presence of a predator and a tax. They have discussed optimal taxation policy but they did not categorize the taxation policy. Wang et al. (2009) studied the asymptotic behaviour of a predator-prey model with stage structure for the predator. Patra et al. (2009) discussed the effect of time-delay on a tritrophic food chain model with Michaelis-Menten type ratio-dependent functional responses.

Pitcher et al. (2009) evaluated the performance of 33 countries for ecosystem-based management (EBM) of fisheries in three fields (principles, criteria and implementation) using quantitative ordination including uncertainty. But they have not considered any empirical model to investigate the performance of 33 countries for ecosystem-based management (EBM) of fisheries. Pomeroy et al. (2009) recommended actions include improved fisheries statistics, resources for provincial fisheries staff, and a coordinated and integrated approach involving a mixed strategy of resource management; resource restoration; economic and community development; and new governance arrangements. It is noted that the recommendations were made with out using any statistical data of the fisheries. Thorpe et al. (2009) concluded that the policy challenges now facing Sierra Leone, particularly the prevention of resource looting through illegal fishing of the offshore stocks and the development of strategies to enable the potential wealth of these fisheries to be captured. But they have not discussed the reference points of the fishery and the statistical evidence in support of their conclusion.

In this paper our objective is to frame a simple bioeconomic model which will be used to investigate the comparative study of the resource stock and harvesting of Maryland's Chesapeake Bay using surplus production models of Verhulst-Schaefer and Gompertz-Fox. The strategy which enhances the revenue function and reduces the cost function is developed using optimal harvesting policy. The biological as well as economical parameters are estimated using the time series catch and effort data of Maryland's Chesapeake Bay. Comparative static effects of different types of equilibrium situations of Maryland's Chesapeake Bay are discussed by achieving the reference points. Finally, the net benefits of Maryland's Chesapeake Bay oyster fishery are obtained by introducing different type of tax policies.

In the above literature survey, it is evident that the work using empirical model which includes time series data of a fishery is not common. Again, the optimal utilization and management of a fishery seems to be more realistic if the conclusions are made through empirical models. For the long run sustainability of a fishery it is necessary to compare the static as well as dynamical effects of harvesting by achieving the reference points of the fishery. It is also necessary to incorporate a suitable tax to the fisherman such that the commercial purpose of the fishery must be fulfilled. In this respect, the present paper is significantly contributed towards the fisheries research. 


\section{The theoretical model}

The function of population growth in a particular area is generally considered as the interactions between environmental factors and the fish stock properties. There are certain environmental conditions for which the total stock of the population is stable. Again, it is possible to express the harvesting of the population in terms of surplus production. In this study, we consider the popular surplus production models of Verhulst-Schaefer and Gompertz-Fox which are particularly developed for assessment of the fishery including the evaluation of the fish stock. But it is not possible to study the implications of fishery management strategy without using a bio-economic model. For this purpose it is necessary to develop a suitable bio-economic model for implementing fishery management tools. The total fishery cost and total revenue are essential in an economic analysis of a particular fishery. It is obvious that the objective of the fisheries management is to maximize the resource rent of the fishery. Economic analysis can help managers to answer the questions of why resources are used as they are, why fisheries are economically inefficient, and how fisheries could be better managed (Hannesson 1993; Jennings et al. 2001).

\subsection{Logistic growth model}

A general biological growth model of a fish stock in the absence of harvesting and other human interference can be expressed as

$$
\frac{d x}{d t}=r x\left(1-\frac{x}{K}\right)
$$

where $\mathrm{r}$ is the intrinsic growth rate, $\mathrm{K}$ is the environmental carrying capacity \& $\mathrm{x}$ is the biomass. Equation (1) implies a parabolic growth curve, where the logistic function is strictly concave from below and exhibits positive growth for all positive values

of $x<K$. The logistic growth function is assumed to describe a process of feedback which controls the growth of the population as its level increases. The logistic growth curve is symmetrical round its point of inflexion. This simple model has been used widely both from a theoretical standpoint and as a convenient empirical curve.

\subsection{Gompertz growth model}

The Gompertz growth model proposed by Gompertz, is given by

$$
\frac{d x}{d t}=r x \log _{e}\left(\frac{K}{x}\right)
$$

The basic difference between the logistic and Gompertz curves is that the logistic is symmetrical while the Gompertz is asymmetrical (inflecting at $\mathrm{x}=\mathrm{K} / \mathrm{e}=0.368 \mathrm{~K}$ ). For a given stock size at time $\mathrm{t}=0$ and a given carrying capacity, the Gompertz model may expect a faster growth of the stock size over time than the Logistic model.

These population growth models implies that an increase in the stock biomass leads to an increase in the catch at the same rate, keeping the fishing effort unchanged.

\subsection{Harvest function}

The harvesting function $H(t)$ is derived using the following two assumptions (Clark, 1990): (a) catch per unit effort is directly proportional to the density of fish, and (b) the density of fish is directly proportional to the abundance $x(t)$.

Thus we assume the following production function, which is commonly used in fishery management as

$$
H(t)=q E x
$$

where $\mathrm{q}$ is the catchability coefficient, $E$ is the fishing effort. Similarly the biomass variable $\mathrm{x}$ is the quantity of harvested fish in a fishing year (to be measured in Bushel).

If the population described by the logistic equation (1) is subject to harvesting at a rate $H(t)$, then equation (1) becomes

$$
\frac{d x}{d t}=r x\left(1-\frac{x}{K}\right)-q E x
$$

At equilibrium, from equation (4) we get the fish biomass $x_{L}$ as 


$$
x_{L}=\frac{K}{r}(r-q E)
$$

Thus from equation (3) harvesting at equilibrium can be obtained as

$$
H_{L}=q E \frac{K}{r}(r-q E) .
$$

Again equation (2) subject to the harvesting function (3) is reduced to

$$
\frac{d x}{d t}=r x \log _{e}\left(\frac{K}{x}\right)-q E x
$$

At equilibrium, from equation (7) we get the fish biomass $x_{G}$ as

$$
x_{G}=K e^{-\frac{q E}{r}} .
$$

Thus from equation (3) harvesting at equilibrium can be obtained as

$$
H_{G}=q K E e^{-\frac{q E}{r}}
$$

\subsection{Economic model}

To attain efficiency in the economic sense, we need to take into account the costs of fishing and revenues that we get from selling the harvested fish. It is necessary to use catch-effort relationship to define revenues and costs as a function of fishing effort. Assuming a constant price, $p$, per unit of fish harvested, the total revenue, $T R$, will be given by; $T R(E)=p H(E)$.

And assuming a constant cost, $C$, per unit of effort, the total costs, $T C$, of fishing is given by; $T C(E)=c E$.

The difference between the total revenue of the fishery and the total fishing costs is known as the sustainable economic rent (profit) provided by the fishery resource at any given level of fishing effort E thus sustainable economic rent can be defined as

$$
\pi(E)=T R(E)-T C(E)
$$

\section{Reference points}

In this section, we derive the analytical expressions of maximum economic yield (MEY), open-access equilibrium (OAE) and the biological equilibrium (MSY) in terms of biological parameters along with economic variables separately for logistic and Gompertz models. These reference points are analyzed for the future management policies of a fishery and sustainable development of ecosystem.

\subsection{Maximum sustainable yield (MSY)}

The equilibrium level of the fishing effort that produces the maximum sustainable yield, found by differentiating equations (6) and (9) with respect to E and setting the result equal to zero gives us maximum sustainable yield. For logistic model

$$
E_{M S Y}=\frac{r}{2 q}
$$

and

$$
H_{M S Y}=\frac{K r}{4} .
$$

For the Gompertz model we get,

$$
E_{M S Y}=\frac{r}{q}
$$


and

$$
H_{M S Y}=\frac{K r}{e} .
$$

3.2 Open access equilibrium (OAE)

The bionomic or open access equilibrium (OAE) can be obtained from the fishery when no economic rent is obtained from the fishery or profit is zero, i.e., $T C(E)=T R(E)$ which gives $p H(E)=c E$. For logistic model,

$$
E_{O A E}=\frac{r}{q}\left(1-\frac{c}{p q K}\right) .
$$

Now to get the yield level at open access let us substitute the effort of open access in the equation (6), which gives

$$
H_{O A E}=\frac{r c}{p q}\left(1-\frac{c}{p q K}\right)
$$

The expressions for Gompertz model are

$$
E_{O A E}=\frac{r}{q} \log _{e}\left(\frac{p q K}{c}\right)
$$

and

$$
H_{O A E}=\frac{r c}{p q} \log _{e}\left(\frac{p q K}{c}\right)
$$

\subsection{Maximum economic yield (MEY)}

The level of harvesting which maximize the profits to the fishery is determined by maximum economic yield (MEY). Maximum economic yield can be obtained from the fishery when the difference between total revenue earned by the fishery and total cost used to harvest is at a maximum. The equilibrium level of fishing effort that produces the maximum economic, rent can be derived by differentiating equation (10) with respect to fishing effort $(E)$. Thus for logistic growth model we get

$$
E_{M E Y}=\frac{r}{2 q}\left(1-\frac{c}{p q K}\right)
$$

and

$$
H_{M E Y}=\frac{r}{4}\left(K-\frac{c^{2}}{p^{2} q^{2} K}\right)
$$

Again, for the Gompertz growth model we have got the following expressions:

$$
E_{M E Y}=\frac{r(1-\omega)}{q} \text { where } \omega e^{\omega}=\frac{c e}{K p q}
$$

and

$$
H_{M E Y}=\frac{r K(1-\omega)}{e^{(1-\omega)}} .
$$




\section{Optimal sustainable yield (OSY)}

The equation that maximize the present value (PV) of the fishery can be expressed as

$$
\max P V=\int_{0}^{\infty} e^{-\delta t}\left(p H(t)-\frac{c}{q x(t)} H(t)\right) d t
$$

subject to $\quad \frac{d x}{d t}=r x(t)\left(1-\frac{x(t)}{K}\right)-H(t)$ and control constraints $0 \leq H \leq H_{\max }$.

Here $\delta$ is the instantaneous annual discount rate.

Hence the current-value Hamiltonian for this control problem is,

$$
L=p H(t)-\frac{c}{q x(t)} H(t)+\lambda\left[r x(t)\left(1-\frac{x(t)}{K}\right)-H(t)\right]
$$

where $\lambda$ is the adjoint variable. The Hamiltonian must be maximized for $H \in\left[0, H_{\max }\right]$. Assuming that the control constraints are not binding (i.e. the optimal solution does not occur at 0 or $H_{\max }$ ) and $\mu(t)=p-c / q x-\lambda$ is called the switching function (see Clark, 1990).

Since Hamiltonian $\mathrm{L}$ is linear in the control variable, the optimal control will be a combination of extreme controls and the singular control. The optimal control $H(t)$ that maximizes L must satisfy the following conditions:

$$
H=H_{\max } \text {, when } \mu(t)>0 \text {, i.e. } \lambda<p-c / q x \text {, }
$$

and

$$
H=0 \text {, when } \mu(t)<0 \text {, i.e. } \lambda>p-c / q x \text {. }
$$

The above condition simply states that the resource should be harvested if and only if the net revenue per unit harvest exceeds the shadow price of the resource stock.

When $\mu(t)=0$, the Hamiltonian $L$ becomes independent of the control variable $H$, i.e., $\partial L / \partial H=0$. This is the necessary condition for the singular control $H^{*}(t)$ to be optimal over the control set $0<H^{*}<H_{\max }$.

Thus the optimal harvesting policy is

$$
H(t)=\left\{\begin{array}{l}
H_{\max } \text { when } \mu(t)>0 \\
0, \text { when } \mu(t)<0 \\
H^{*} \text { when } \mu(t)=0
\end{array}\right.
$$

Again the optimal stock level is such that the rent earned by the stock equals the social rate of discount. The optimal stock solution is given by

$$
x^{*}=\frac{K}{4}\left(1-\frac{\delta}{r}\right)+\frac{c}{4 p q}+\sqrt{\left(\frac{K}{4 r p}\right)^{2}\left(p(\delta-r)-\frac{c r}{q K}\right)^{2}+\left(\frac{K}{4 r p}\right)^{2} \frac{8 r p \delta c}{K q}} .
$$

Proceeding in the similar manner it is possible to obtain the optimal stock corresponding to Gompertz model by solving the following equation:

$$
\log _{e}\left(\frac{K}{x}\right)-\left(1+\frac{\delta}{r}\right)\left(1-\frac{c}{p q x}\right)=0
$$

It is noted that the optimal stock solution for both the models depends only on the bioeconomic parameters c, p, q, $\delta$, $\mathrm{r}$ and $\mathrm{K}$. 
Consequently, the optimal yield and optimal effort are respectively obtained as

$$
H^{*}=r x^{*}\left(1-\frac{x^{*}}{K}\right) \text { and } E^{*}=\frac{H^{*}}{q x^{*}} .
$$

Thus the optimal profit of Maryland’s Chesapeake Bay oyster fishery is given by

$$
\pi\left(p, q, K, r, c, x^{*}\right)=p H^{*}-\frac{c}{q x^{*}} H^{*} .
$$

The present value of profits of Maryland's Chesapeake Bay oyster fishery is reduced to

$$
P V=\int_{0}^{\infty}(\pi) e^{-\delta t} d t=\frac{1}{\delta} \pi
$$

\section{Tax policies to achieve reference points}

Management of fisheries has the potential to yield a socially optimal outcome through proper utilization of different types of tax policies. These include maximization of fishing production or revenues; minimize catch fluctuations, to avoid the risk of collapse of the resource, etc. The manager has two kinds of tools available: first one is technical tool which includes effort or selective regulations; second is economic tool which includes subsidies and taxes. The effectiveness of each of these tools varies in case of achieving the purpose of the fishery managers and has significant implications for the control of the stock. We can take taxes in the form of license fees, and are levied prior to any harvest and effort being expended, or in the form of a per unit effort tax. Again, we are concerned about several problems that are imposed for fishery managers due to input taxes such as they may not have a predicable effect on the level of effort expended in the fishery. If the tax changes the relative cost of inputs, fishers will substitute higher cost for lower cost inputs. This result will have an effect on the efficiency of fishers as now they will be using inputs in nonoptimal proportions, that is, they become inefficient transferring a larger amount of fishery rent to cost.

We can consider the outcome of open access fisheries in a case of market failure which ultimately sends wrong message to the economy. Thus tax policies are considered to be a suitable measure to manage fishery. It can be argued that the market failure is a result of ill defined property rights to the resources. Therefore introduction of suitable tax policies are of great concern to overcome property rights problems. It may be assumed that fishery managers should set taxes on landings, or effort, such that perceived bionomic equilibrium for the fleet will be the optimal stock. Otherwise if the resource stock is driven below the optimal stock then the revenue earned by the fishery will not exceed the cost used for fishing. In order to apply taxes precisely, we have to be conscious about the continuous adjustments required to implement the policies due to repeated fluctuations in resource and economic conditions. Additionally, as the fisheries are not identical in order to achieve the optimum outcome we should have separate tax for each fishery which is practically impossible due to the insufficient information obtained from the fishery. Again, the control through the use of taxes is politically unacceptable. Hence more gradual tax programmes, as a means of control in fisheries, are appropriate, in which the taxes are initially imposed at a low level, and in which there are successive turns of the tax rotation.

Let us now assume that the Maryland's Chesapeake Bay oyster fishery is in open access situation and the controlling agency of Maryland's Chesapeake Bay oyster fishery levis a tax $T(>0)$ in order to achieve $H_{M S Y}, H_{O S Y}$ or $H_{M E Y}$ by incorporating the fishing effort equally $E_{M S Y}, E_{O S Y}$ or $E_{M E Y}$. Here we derive the expressions to calculate different type of tax policies using $H_{M S Y}$ and $E_{M S Y}$ only but we evaluate the following three types of tax to achieve MSY, OSY and MEY for the Maryland's Chesapeake Bay oyster fishery.

\section{Landing tax}

If $T(>0)$ is the landing tax that needs to be imposed to achieve $H_{M S Y}, H_{O S Y}$ or $H_{M E Y}$ by incorporating the fishing effort equally $E_{M S Y}, E_{O S Y}$ or $E_{M E Y}$ then we get the following equation:

$$
(p-T) H_{M S Y}=c E_{M S Y} \text { which gives } T=p-c E_{M S Y} / H_{M S Y}
$$

The intercept between $T R_{1}=(p-T) H$ and $T C=c E$ will give us $\left(E_{M S Y},(p-T) H_{M S Y}\right)$. 


\section{Effort tax}

If $T(>0)$ is the effort tax that needs to be imposed to achieve $H_{M S Y}, H_{O S Y}$ or $H_{M E Y}$ by incorporating the fishing effort equally $E_{M S Y} E_{O S Y}$ or $E_{M E Y}$ then we get the following equation:

$$
p H_{M S Y}=(c+T) E_{M S Y} \text { which gives } T=\left[p H_{M S Y} / E_{M S Y}\right]-c
$$

The intercept between $T R=p H$ and $T C_{1}=(c+T) E$ will give us $\left(E_{M S Y}, p H_{M S Y}\right)$.

Entry tax

If $T(>0)$ is the entry tax that needs to be imposed to achieve $H_{M S Y}, H_{O S Y}$ or $H_{M E Y}$ by incorporating the fishing effort equally $E_{M S Y}, E_{O S Y}$ or $E_{M E Y}$ then we get the following equation:

$$
p H_{M S Y}=c E_{M S Y}+T \text { which gives } T=p H_{M S Y}-c E_{M S Y}
$$

The intercept between $T R=p H$ and $T C_{1}=c E+T$ will give us $\left(E_{M S Y}, p H_{M S Y}\right)$.

The result of different kind of taxes to achieve MSY, OSY and MEY are given in Table no. 7, 10, 13 and 16. Following figures are drawn to achieve MEY using the tax values given in Table no. $7 \& 10$. It is clearly observed from the figures that maximum economic yield 4358 bushel for logistic growth model and 4225.64 bushel for Gompertz growth model are achieved through incorporating tax values in fishing effort (considered as boat days by gear type).

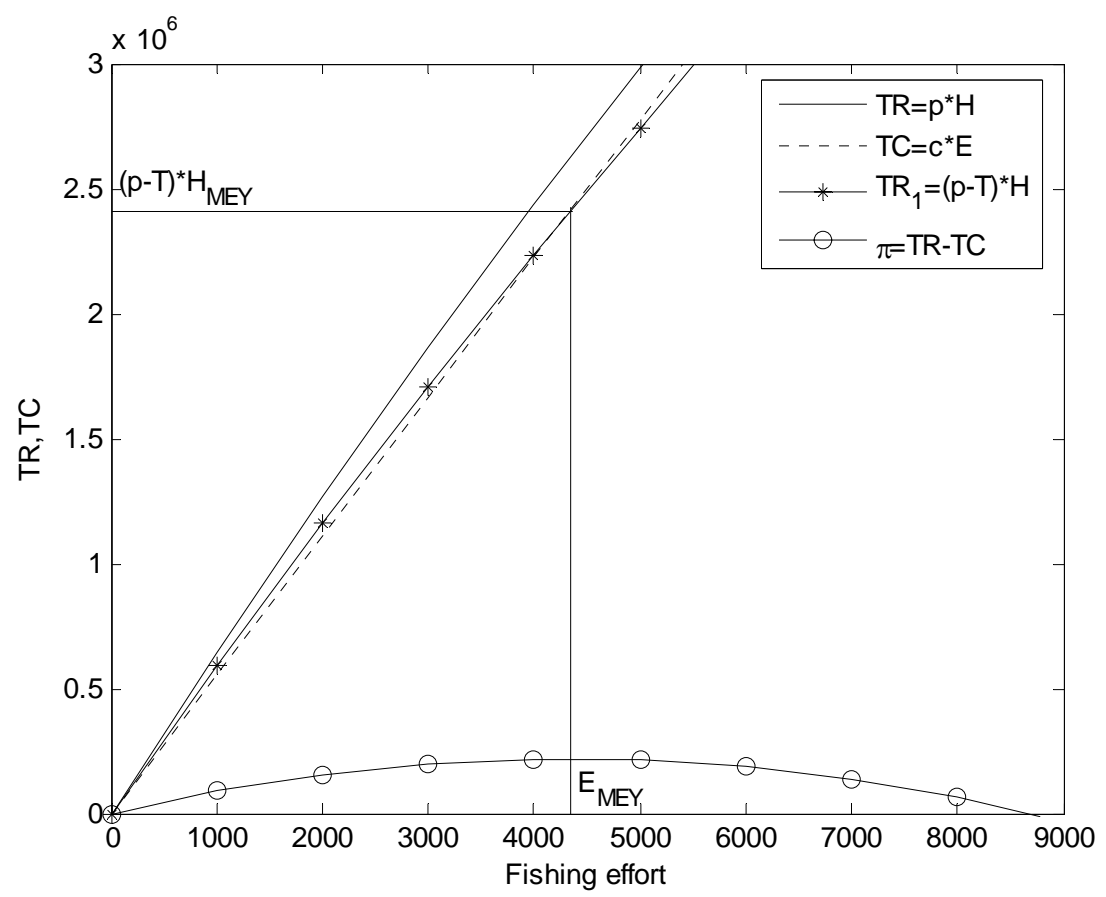

Figure 1. Landing tax to achieve MEY corresponding to the Logistic growth model using the effort data as boat days by gear type of Maryland's Chesapeake Bay oyster fishery 


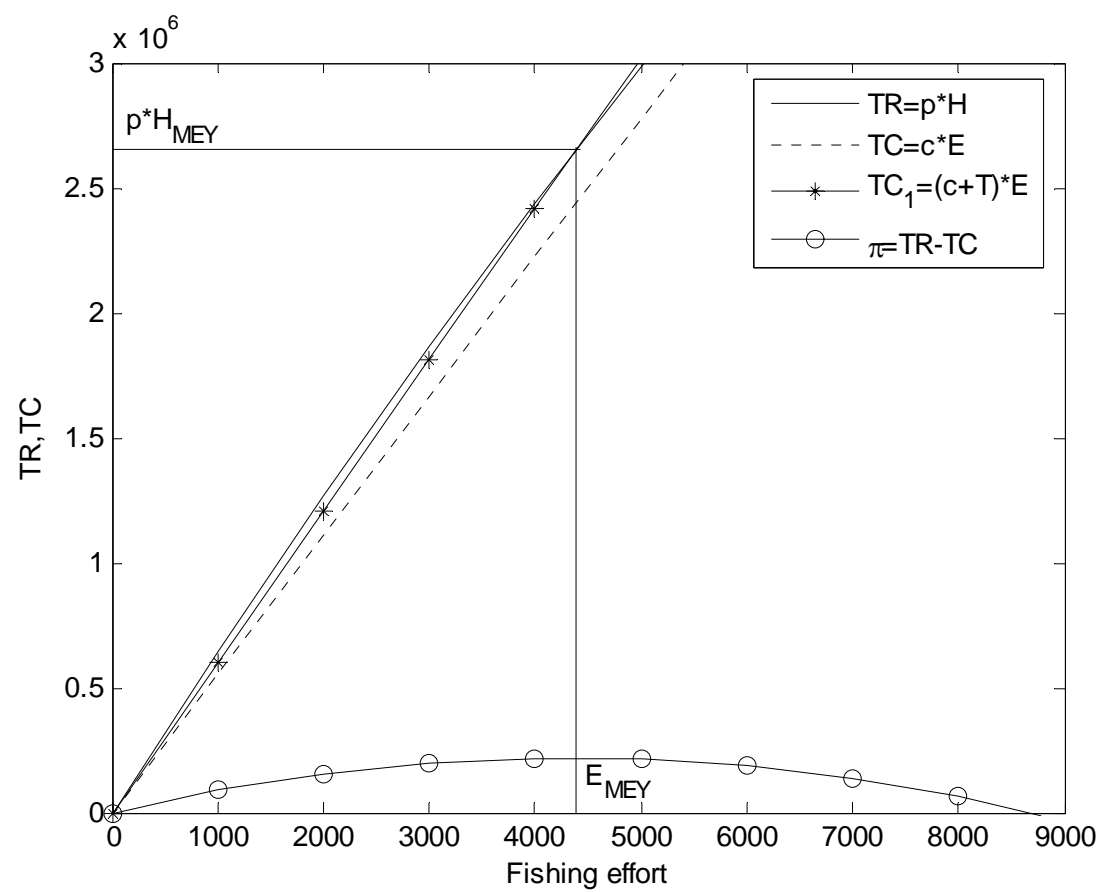

Figure 2. Effort tax to achieve MEY corresponding to the Logistic growth model using the effort data as boat days by gear type of Maryland’s Chesapeake Bay oyster fishery

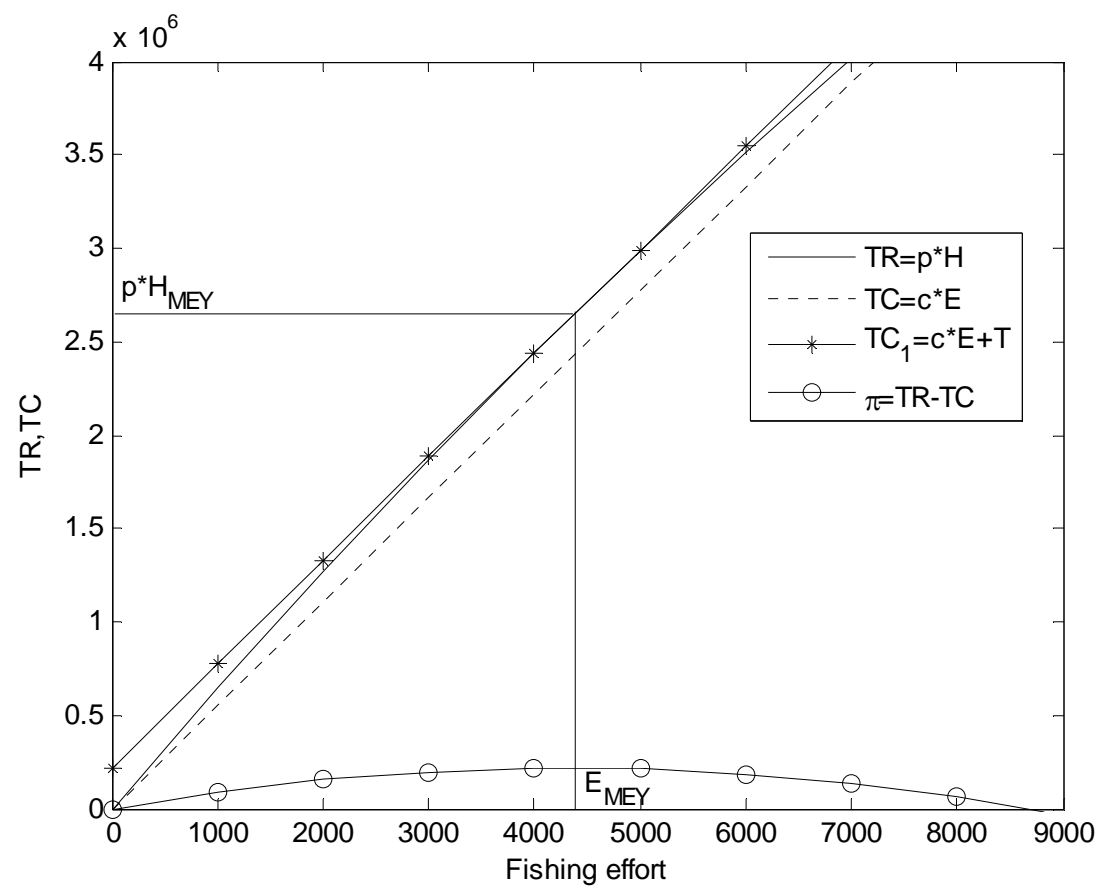

Figure 3. Entry tax to achieve MEY corresponding to the Logistic growth model using the effort data as boat days by gear type of Maryland’s Chesapeake Bay oyster fishery 


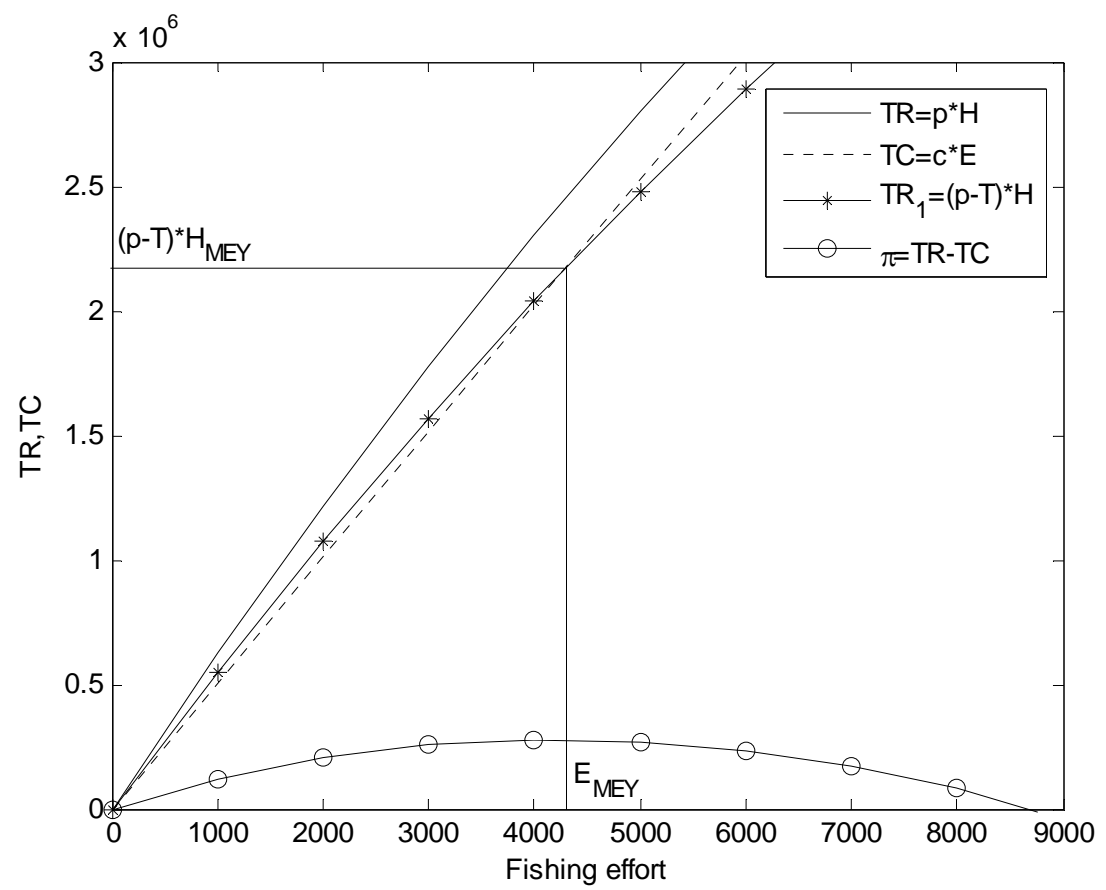

Figure 4. Landing tax to achieve MEY corresponding to the Gompertz growth model using the effort data as boat days by gear type of Maryland's Chesapeake Bay oyster fishery

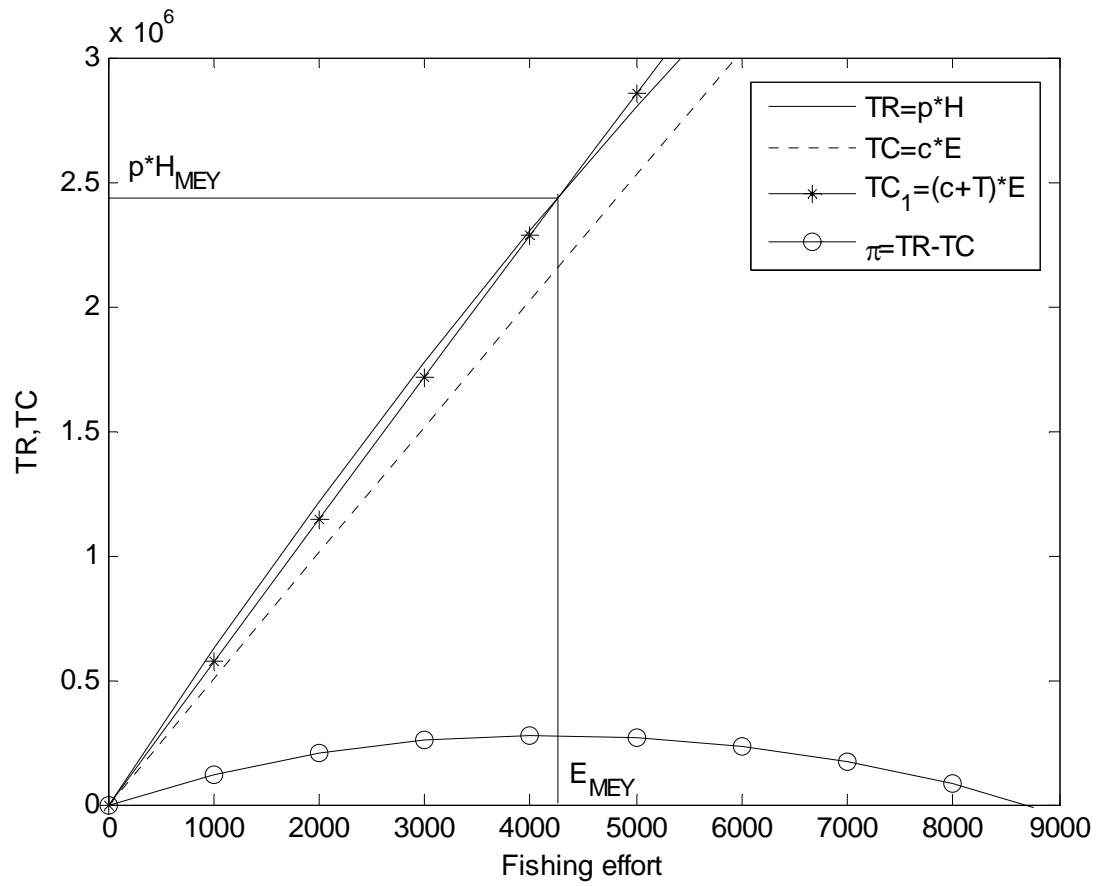

Figure 5. Effort tax to achieve MEY corresponding to the Gompertz growth model using the effort data as boat days by gear type of Maryland's Chesapeake Bay oyster fishery 


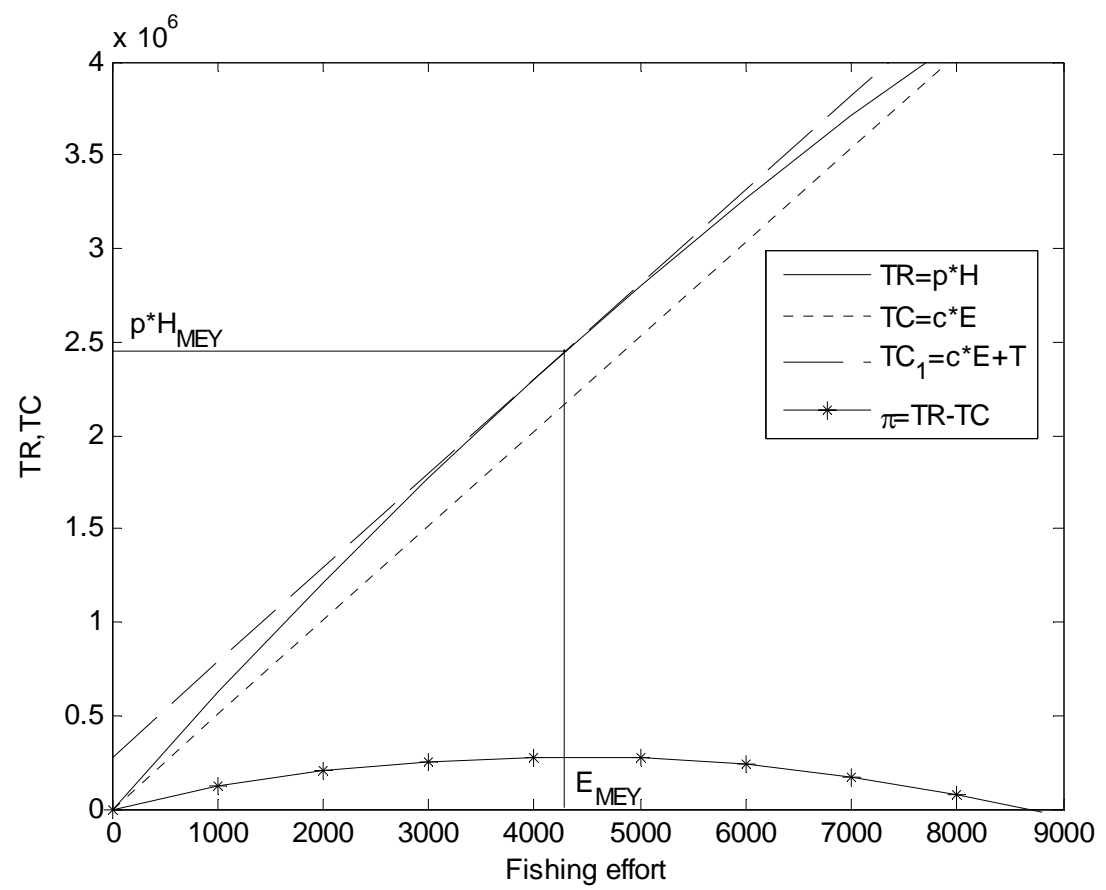

Figure 6. Entry tax to achieve MEY corresponding to the Gompertz growth model using the effort data as boat days by gear type of Maryland's Chesapeake Bay oyster fishery

\section{The empirical model}

The regression analysis results were obtained using the empirical model described in this section. The parameters of the biological growth models are estimated using the time series catch and effort data of Maryland's Chesapeake Bay. Here in this model we consider time series data of Maryland's Chesapeake Bay from the year 1989 to 2006. Generally we consider catch per unit effort is directly proportional to the stock of biomass i.e., $S \propto x$, where $S$ denotes the catch per unit effort and $x$ denotes the stock of the population at time $t$.

Using the equation (1) we have the following equation,

$$
\frac{\dot{S}}{S}=r-\frac{r}{q K} S-q E
$$

From the finite difference approximation $\dot{S}$ can be written as

$$
\frac{d S}{d t} \approx \frac{S_{t+1}-S_{t-1}}{2}
$$

Thus,

$$
\frac{S_{t+1}-S_{t-1}}{2 S_{t}}=r-\frac{r}{q K} S_{t}-q E_{t}
$$

It is noted that we can easily calculate CPUE using the time series data of catch and effort, consequently a linear regression of $Y=\left(S_{t+1}-S_{t-1}\right) / 2 S_{t}$ can be obtained using two independent variables $S$ and $E$ which yield the following equation with the error term $\varepsilon_{1}$ committed to the model during the linear regression analysis using logistic growth model,

$$
Y=\alpha_{1}+\alpha_{2} S_{t}+\alpha_{3} E_{t}+\varepsilon_{1}
$$

where $\alpha_{1}=r$,

$$
\alpha_{2}=-\frac{r}{q K}
$$




$$
\alpha_{3}=-q
$$

Thus it is possible to calculate value of the biological parameters of Logistic growth model using the estimated value of $\alpha_{1}, \alpha_{2}$ and $\alpha_{3}$.

Again using the equation (2) we can write

$$
\frac{\dot{S}}{S}=r \log _{e}^{q K}-r \log _{e}^{S}-q E .
$$

Thus, for the Gompertz growth model we have the following equation for estimation,

$$
Y=\beta_{1}+\beta_{2} S_{t}+\beta_{3} E_{t}+\varepsilon_{2},
$$

where

$$
\begin{aligned}
& \beta_{1}=r \log _{e}^{q K}, \\
& \beta_{2}=-r, \\
& \beta_{3}=-q,
\end{aligned}
$$

and $\varepsilon_{2}$ be the error committed to the model during the linear regression analysis using Gompertz growth model. Consequently it is possible to calculate value of the biological parameters of Gompertz growth model using the estimated value of $\beta_{1}, \beta_{2}$ and $\beta_{3}$.

Prices are considered as the interaction between the demand and supply of the resource. It is possible to examine the relative profit through allocating resources between various outputs and allow an optimal decision regarding to the relative production quantities for the fishery managers. Prices also reflect the relative quantities in which consumers would like to consume resources. It is assumed that demand is linear in price and stationary, the inverse demand or willing to pay (WTP) function of harvest can be expressed as

$$
p=d_{1}+d_{2} H(t)
$$

\subsection{Results of estimation}

In order to estimate the biological parameters of Logistic and Gompertz models we mainly use time series harvest and effort data of Maryland's Chesapeake Bay oyster fishery (Wieland, 2007) from1989 to 2006. For the purpose of estimation we have two different types of effort data namely boat days by gear type and man days by gear type.

We divide this section in two parts. In the first part we consider effort data as boat days by gear type and estimation is done for both the biological growth models. Man days by gear type is considered as effort data for the second part and both the biological models are considered for estimation. The estimation has been done using ordinary least squares method and results are as follows:

Table1. Estimation of the biological parameters of Logistic growth model using the effort data as boat days by gear type of Maryland's Chesapeake Bay oyster fishery

\begin{tabular}{|c|c|c|c|c|}
\hline Variable & Estimate & Std. error & t-Statistics & P-value \\
\hline$\alpha_{1}$ & 0.0725736 & 0.209626 & 0.346206 & 0.734727 \\
\hline$\alpha_{2}$ & -0.00244829 & 0.0173103 & -0.141435 & 0.889694 \\
\hline$\alpha_{3}$ & $-1.27039 \times 10^{-6}$ & $2.81883 \times 10^{-6}$ & -0.450681 & 0.659644 \\
\hline
\end{tabular}

Rsquared $=0.0161406$,

AdjustedRSquared $=-0.135222$,

EstimatedVariance $=0.0167142$.

Thus the consequent value of biological parameters is as follows:

$$
r=0.0725736, \quad K=2.33334 \times 10^{7}, \mathrm{q}=1.27039 \times 10^{-6} .
$$


Table2. Estimation of the biological parameters of Gompertz growth model using the effort data as boat days by gear type of Maryland's Chesapeake Bay oyster fishery

\begin{tabular}{|c|c|c|c|c|}
\hline Variable & Estimate & Std. error & t-Statistics & P-value \\
\hline$\beta_{1}$ & 0.159956 & 0.493311 & 0.324251 & 0.750906 \\
\hline$\beta_{2}$ & -0.0474837 & 0.200823 & -0.236446 & 0.816771 \\
\hline$\beta_{3}$ & $-1.29835 \times 10^{-6}$ & $2.81639 \times 10^{-6}$ & -0.460999 & 0.652417 \\
\hline
\end{tabular}

Rsquared $=0.0188461$,

AdjustedRSquared $=-0.132101$,

EstimatedVariance $=0.0166683$.

Thus the consequent value of biological parameters is as follows:

$$
r=0.0474837, \quad K=2.23665 \times 10^{7}, \mathrm{q}=1.29835 \times 10^{-6} .
$$

Table3. Estimation of the biological parameters of Logistic growth model using the effort data as man days by gear type of Maryland's Chesapeake Bay oyster fishery

\begin{tabular}{|c|c|c|c|c|}
\hline Variable & Estimate & Std. error & t-Statistics & P-value \\
\hline$\alpha_{1}$ & 0.073271 & 0.176661 & 0.414755 & 0.685084 \\
\hline$\alpha_{2}$ & -0.00210312 & 0.0255024 & -0.0824677 & 0.935531 \\
\hline$\alpha_{3}$ & $-8.93172 \times 10^{-7}$ & $1.16437 \times 10^{-6}$ & -0.767089 & 0.456734 \\
\hline
\end{tabular}

Rsquared $=0.0458702$,

AdjustedRSquared $=-0.100919$,

EstimatedVariance $=0.0095219$.

Thus the consequent value of biological parameters is as follows:

$$
r=0.073271, \quad K=3.90061 \times 10^{7}, \mathrm{q}=8.93172 \times 10^{-7} .
$$

Table 4. Estimation of the biological parameters of Gompertz growth model using the effort data as man days by gear type of Maryland's Chesapeake Bay oyster fishery

\begin{tabular}{|c|c|c|c|c|}
\hline Variable & Estimate & Std. error & t-Statistics & P-value \\
\hline$\beta_{1}$ & 0.119009 & 0.296561 & 0.401296 & 0.694721 \\
\hline$\beta_{2}$ & -0.0315917 & 0.154788 & -0.204096 & 0.841439 \\
\hline$\beta_{3}$ & $-9.42475 \times 10^{-7}$ & $1.16451 \times 10^{-6}$ & -0.809329 & 0.43289 \\
\hline
\end{tabular}

Rsquared $=0.0484201$,

AdjustedRSquared $=-0.0979768$,

EstimatedVariance $=0.00949645$.

Thus the consequent value of biological parameters is as follows:

$$
r=0.0315917, \quad K=4.58942 \times 10^{7}, \mathrm{q}=9.42475 \times 10^{-7} .
$$

It is possible to estimate inverse demand function by using price and harvest data through ordinary least squares method.

Table 5. Estimation of price of oyster fish using the harvest and price data of Maryland's Chesapeake Bay oyster fishery

\begin{tabular}{|c|c|c|c|c|}
\hline Variable & Estimate & Std. error & t-Statistics & P-value \\
\hline$d_{1}$ & 23.1238 & 1.85659 & 12.455 & $1.19776 \times 10^{-9}$ \\
\hline$d_{2}$ & $-8.00178 \times 10^{-6}$ & $7.56569 \times 10^{-6}$ & -1.05764 & 0.305927 \\
\hline
\end{tabular}

Rsquared $=0.0653443$,

AdjustedRSquared $=0.00692834$,

EstimatedVariance $=16.0392$. 
Thus the price $(p)$ of oyster fish of the Maryland's Chesapeake Bay oyster fishery used in our study is $p=\$ 22.1015$, estimated price of oyster fish corresponding to the year 2006, $(H(2006)=127761)$.

Generally the unit cost of fishing $(c)$ composed of labour costs, capital, materials, energy, fuel costs and indirect cost. Again indirect costs incorporate reported maintenance, repair and replacement costs. But these data are not available from the source. Thus the unit cost of fishing is estimated based on the assumption that Maryland's Chesapeake Bay oyster fishery is in open access equilibrium and we consider that the effort in open access equilibrium is assumed to be equal with the effort level in 2006. If we consider fishing effort as boat days by gear type then corresponding to the Logistic and Gompertz model respective unit cost of fishing are \$555.187 and \$505.719. Again for fishing effort as man days by gear type the unit cost of fishing for Logistic and Gompertz models are respectively $\$ 630.02$ and $\$ 635.855$. The price of oyster fishery and unit cost of fishing are assumed to be constant over the years.

\subsection{Results of bioeconomic model}

Static biological equilibrium (MSY), economic optimum (MEY) and economic equilibrium for open-access fisheries (OAE) evaluated for both the models are presented in the following tables, using the estimated biological parameters of Maryland's Chesapeake Bay oyster fishery along with the price and harvesting cost of oyster fish. Total revenue of the Maryland's Chesapeake Bay oyster fishery, total operational cost of oyster fishing and economic rent of the fishery are also presented in the tables.

Table 6. MSY, MEY, OAE levels and economic rents for Maryland's Chesapeake Bay oyster fishery using Logistic growth model, taking effort data as boat days by gear type

\begin{tabular}{|l|c|c|c|}
\hline \multicolumn{1}{|c|}{ Harvest condition } & MSY & MEY & OAE \\
\hline $\begin{array}{l}\text { Fishing effort (boat days } \\
\text { by gear type) }\end{array}$ & 28563.5 & 4358 & 8716 \\
\hline $\begin{array}{l}\text { Harvest (measured in } \\
\text { Bushel) }\end{array}$ & 423347 & 119327 & 218945 \\
\hline $\begin{array}{l}\text { Total revenue (TR) } \\
\text { (measured in dollar) }\end{array}$ & 9356610 & 2637310 & 4839010 \\
\hline $\begin{array}{l}\text { Total operational cost } \\
\text { (TC) (measured in } \\
\text { dollar) }\end{array}$ & 15858100 & 2419510 & 4839010 \\
\hline $\begin{array}{l}\text { Economic rent (TR-TC) } \\
\text { of the fishery. }\end{array}$ & -6501490 & 217806 & 0 \\
\hline
\end{tabular}

Table 7. Tax policies to achieve MSY, OSY (considering 1\% discount rate) and MEY levels for Maryland's Chesapeake Bay oyster fishery using Logistic growth model, taking effort data as boat days by gear type

\begin{tabular}{|c|c|c|c|}
\hline & Landing tax & Effort tax & Entry tax \\
\hline Tax to achieve MSY & -15.3573 & -227.615 & -6501490 \\
\hline Tax to achieve OSY & 1.70775 & 46.4908 & 216745 \\
\hline Tax to achieve MEY & 1.82528 & 49.9784 & 217806 \\
\hline
\end{tabular}

Table8. Optimal values of biomass, effort, harvest and profit of Maryland's Chesapeake Bay oyster fishery using Logistic growth model, taking effort data as boat days by gear type for different discounting rates

\begin{tabular}{|c|c|c|c|c|}
\hline$\delta$ & $x^{*}$ & $H^{*}$ & $E^{*}$ & Profits \\
\hline 0 & $2.15534 \times 10^{7}$ & 119327 & 4358 & 217806 \\
\hline 0.01 & $2.14292 \times 10^{7}$ & 126919 & 4662.11 & 216745 \\
\hline 0.05 & $2.10617 \times 10^{7}$ & 148814 & 5561.76 & 201188 \\
\hline 0.1 & $2.07769 \times 10^{7}$ & 165206 & 6259.03 & 176361 \\
\hline$\infty$ & $1.97734 \times 10^{7}$ & 218945 & 8716 & 0 \\
\hline
\end{tabular}


Table 9. MSY, MEY, OAE levels and economic rents for Maryland's Chesapeake Bay oyster fishery using Gompertz growth model, taking effort data as boat days by gear type

\begin{tabular}{|l|c|c|c|}
\hline \multicolumn{1}{|c|}{ Harvest condition } & MSY & MEY & OAE \\
\hline $\begin{array}{l}\text { Fishing effort (boat days } \\
\text { by gear type) }\end{array}$ & 36572.3 & 4225.64 & 8716 \\
\hline $\begin{array}{l}\text { Harvest (measured in } \\
\text { Bushel) }\end{array}$ & 390704 & 109321 & 199437 \\
\hline $\begin{array}{l}\text { Total revenue (TR) } \\
\text { (measured in dollar) }\end{array}$ & 8635150 & 2416160 & 4407850 \\
\hline $\begin{array}{l}\text { Total operational cost } \\
\text { (TC) (measured in } \\
\text { dollar) }\end{array}$ & 18495300 & 2136990 & 4407850 \\
\hline $\begin{array}{l}\text { Economic rent (TR-TC) } \\
\text { of the fishery. }\end{array}$ & -9860190 & 279170 & 0 \\
\hline
\end{tabular}

Table10. Tax policies to achieve MSY, OSY (considering 1\% discount rate) and MEY levels for Maryland's Chesapeake Bay oyster fishery using Gompertz growth model, taking effort data as boat days by gear type

\begin{tabular}{|c|c|c|c|}
\hline & Landing tax & Effort tax & Entry tax \\
\hline Tax to achieve MSY & -25.237 & -269.608 & -9860190 \\
\hline Tax to achieve OSY & 2.32329 & 59.4055 & 276479 \\
\hline Tax to achieve MEY & 2.55367 & 66.0658 & 279170 \\
\hline
\end{tabular}

Table11. Optimal values of biomass, effort, harvest and profit of Maryland's Chesapeake Bay oyster fishery using Gompertz growth model, taking effort data as boat days by gear type for different discounting rates

\begin{tabular}{|c|c|c|c|c|}
\hline$\delta$ & $x^{*}$ & $H^{*}$ & $E^{*}$ & Profits \\
\hline 0 & $1.99259 \times 10^{7}$ & 109321 & 4225.64 & 279167 \\
\hline 0.01 & $1.96939 \times 10^{7}$ & 119003 & 4654.1 & 276479 \\
\hline 0.05 & $1.90946 \times 10^{7}$ & 143398 & 5784.14 & 244153 \\
\hline 0.1 & $1.87013 \times 10^{7}$ & 158929 & 6545.47 & 202402 \\
\hline$\infty$ & $1.76237 \times 10^{7}$ & 199437 & 8716 & 0 \\
\hline
\end{tabular}

Table12.MSY, MEY, OAE levels and economic rents for Maryland's Chesapeake Bay oyster fishery using Logistic growth model taking, effort data as man days by gear type

\begin{tabular}{|l|c|c|c|}
\hline \multicolumn{1}{|c|}{ Harvest condition } & MSY & MEY & OAE \\
\hline $\begin{array}{l}\text { Fishing effort (man days } \\
\text { by gear type) }\end{array}$ & 41017.3 & 7456.5 & 14913 \\
\hline $\begin{array}{l}\text { Harvest (measured in } \\
\text { Bushel) }\end{array}$ & 714504 & 236166 & 425107 \\
\hline $\begin{array}{l}\text { Total revenue (TR) } \\
\text { (measured in dollar) }\end{array}$ & 15791600 & 5219620 & 9395490 \\
\hline $\begin{array}{l}\text { Total operational cost } \\
\text { (TC) (measured in } \\
\text { dollar) }\end{array}$ & 25841700 & 4697750 & 9395490 \\
\hline $\begin{array}{l}\text { Economic rent (TR-TC) } \\
\text { of the fishery. }\end{array}$ & -10050100 & 521870 & 0 \\
\hline
\end{tabular}

Table13. Tax policies to achieve MSY, OSY (considering 1\% discount rate) and MEY levels for Maryland's Chesapeake Bay oyster fishery using Logistic growth model taking, effort data as man days by gear type

\begin{tabular}{|c|c|c|c|}
\hline & Landing tax & Effort tax & Entry tax \\
\hline Tax to achieve MSY & -14.0659 & -245.022 & -10050100 \\
\hline Tax to achieve OSY & 2.069 & 65.0697 & 519292 \\
\hline Tax to achieve MEY & 2.20976 & 69.9886 & 521870 \\
\hline
\end{tabular}


Table14. Optimal values of biomass, effort, harvest and profit of Maryland's Chesapeake Bay oyster fishery using Logistic growth model taking, effort data as man days by gear type for different discounting rates

\begin{tabular}{|c|c|c|c|c|}
\hline$\delta$ & $x^{*}$ & $H^{*}$ & $E^{*}$ & Profits \\
\hline 0 & $3.54607 \times 10^{7}$ & 236166 & 7456.5 & 521870 \\
\hline 0.01 & $3.52115 \times 10^{7}$ & 250988 & 7980.55 & 519292 \\
\hline 0.05 & $3.44731 \times 10^{7}$ & 293537 & 9533.38 & 481383 \\
\hline 0.1 & $3.39013 \times 10^{7}$ & 325084 & 10736 & 420917 \\
\hline$\infty$ & $3.19152 \times 10^{7}$ & 425107 & 14913 & 0 \\
\hline
\end{tabular}

Table15.MSY, MEY, OAE levels and economic rents for Maryland's Chesapeake Bay oyster fishery using Gompertz growth model, taking effort data as man days by gear type

\begin{tabular}{|l|c|c|c|}
\hline \multicolumn{1}{|c|}{ Harvest condition } & MSY & MEY & OAE \\
\hline $\begin{array}{l}\text { Fishing effort (man days } \\
\text { by gear type) }\end{array}$ & 33519.9 & 6474.37 & 3968.3 \\
\hline $\begin{array}{l}\text { Harvest (measured in } \\
\text { Bushel) }\end{array}$ & 533379 & 5102260 & 8691080 \\
\hline $\begin{array}{l}\text { Total revenue (TR) } \\
\text { (measured in dollar) }\end{array}$ & 11788500 & 4116760 & 8691080 \\
\hline $\begin{array}{l}\text { Total operational cost } \\
\text { (TC) (measured in } \\
\text { dollar) }\end{array}$ & 21313800 & 985501 & 0 \\
\hline $\begin{array}{l}\text { Economic rent (TR-TC) } \\
\text { of the fishery. }\end{array}$ & -9525340 & & 0 \\
\hline
\end{tabular}

Table16.Tax policies to achieve MSY, OSY (considering 1\% discount rate) and MEY levels for Maryland’s Chesapeake Bay oyster fishery using Gompertz growth model, taking effort data as man days by gear type

\begin{tabular}{|c|c|c|c|}
\hline & Landing tax & Effort tax & Entry tax \\
\hline Tax to achieve MSY & -17.8585 & -284.17 & -9525340 \\
\hline Tax to achieve OSY & 3.73644 & 129.367 & 965155 \\
\hline Tax to achieve MEY & 4.2689 & 152.216 & 985501 \\
\hline
\end{tabular}

Table17. Optimal values of biomass, effort, harvest and profit of Maryland's Chesapeake Bay oyster fishery using Gompertz growth model, taking effort data as man days by gear type for different discounting rates

\begin{tabular}{|c|c|c|c|c|}
\hline$\delta$ & $x^{*}$ & $H^{*}$ & $E^{*}$ & Profits \\
\hline 0 & $3.78333 \times 10^{7}$ & 230856 & 6474.37 & 985502 \\
\hline 0.01 & $3.67364 \times 10^{7}$ & 258309 & 7460.59 & 765155 \\
\hline 0.05 & $3.4373 \times 10^{7}$ & 313899 & 9689.54 & 590787 \\
\hline 0.1 & $3.31196 \times 10^{7}$ & 341320 & 10934.7 & 0 \\
\hline$\infty$ & $3.05258 \times 10^{7}$ & 393235 & 13668.3 & \\
\hline
\end{tabular}

\section{Conclusion}

In this paper we intend to provide a framework for conservation of the resource and economic viability of the Maryland's Chesapeake Bay oyster fishery. In general the framework consists of several management plans which are broad and comprehensive in scope. Management plans include all relevant aspects of the fishery for biological as well as economical perspective. It is clear from our study that the oyster stock is not sustainable with respect to all reference points and for conservation, restoration, and enhancement of oyster resource it is necessary to enforce sustainability with respect to the reference points. We have used Verhulst-Schaefer and Gompertz-Fox models to describe the development of the fishery. The biological and economical parameters of the bioeconomic models are estimated through two different types of effort data. To maximize the yield and resource rent optimal sustainable strategy is used and all the results are obtained in numerical with proper units. It is evident from the obtained results that the existing fishing effort of the oyster fishery should be reduced to archive MSY otherwise total operational cost of the fishery will exceed total revenue earned by the fishery consequently the fishery will not be able to fulfil 
commercial purpose. From the estimated results it is possible to obtain a rough idea of fishing effort to achieve MEY, in this regard it should be remembered that at the present scenario maximum economic yield (MEY) is globally accepted fishery management tool. Tax policies are discussed and it is found that subsidies should be given to the harvest effort to achieve MSY. Here it is noted that for landing, effort and entry tax subsidy is necessary to achieve MSY. Therefore, it is not only feasible to assess the biological, social, and economic impacts of existing oyster resource but also provide appropriate measures to maintain long run sustainability through the obtained results.

It is observed from Tables $6 \& 8$ and $9 \& 11$ that the values of $H_{M E Y}$ and fishing effort applied to achieve MEY for Maryland's Chesapeake Bay oyster fishery obtained using dynamic model with zero discounting rate are equal to the values of $H_{M E Y}$ and fishing effort applied to achieve MEY obtained by means of the static model for the same fishery. Again it is noted that the values of $H_{O A E}$ and fishing effort applied to achieve OAE for Maryland's Chesapeake Bay oyster fishery obtained using dynamic model with infinite discounting rate are equal to the values of $H_{O A E}$ and fishing effort applied to achieve OAE obtained by means of the static model for the same fishery. It is also observed from table $9 \& 11$ that when rate of discounting is gradually increased up to $\delta=0.1$, corresponding harvest of the resource increases and the consequent fishing effort is simultaneously increased. As a result the stock of the resource is gradually decreases as the rate of discounting increases. It depicts from table $9 \& 11$ that the fishing effort tends to its maximum level when rate of discounting is considered to be infinite where as for zero discounting rate, the fishing effort is at its maximum value as expected. It is interesting to see that the revenue earned from the fishery is gradually decreased as the rate of discounting increased and at the infinite discounting rate i.e., at the open access equilibrium, revenue earned from the fishery is tend to zero where as at the zero discounting rate the revenue earned from the fishery takes its maximum level. Again, it should be mentioned that it is not possible to impose tax regulations in open access equilibrium situation of the fishery since individual fishers attempt to maximize their income using maximum level of fishing effort. In this situation, it is necessary to enforce strong regulatory agency to reduce wasteful harvesting practices.

We concentrate mainly on the harvesting problem in a deterministic framework. The evolution of natural stocks, however, is seldom deterministic; it is subject to stochastic perturbations due to environmental and other factors. Thus a future research problem would be considered in stochastic environment. Another area to explore is to determine optimal harvesting strategies using game theory.

\section{Acknowledgement}

Acknowledgement: Research of T. K. Kar is supported by the Council of Scientific and Industrial Research (C S I R), India (Grant no. 25(0160)/ 08 / EMR-II dated 17.01.08)

\section{References}

Bjorndal T., 1987. Production economics and optimal stock size in a North Atlantic fishery, Scand. J. of Economics, Vol. 89, No. 2, pp. 145-164.

Chaudhuri K. S. and Johnson T., 1990. Bioeconomic dynamics of a fishery modelled as an S-system, Math. Biosci., Vol. 99, pp. 231-249.

Chaudhuri. K. S. and Saha Ray S., 1996. On the combined harvesting of a prey-predator system, J. Biol. Syst., Vol. 4, No. 3, pp. 373-389.

Clark C.W. and Munro G.R., 1975. Economics of fishing and modern capital theory: a simplified approach, Journal of

Environmental Economics and Management, Vol. 2, pp. 92-106.

Clark C.W., 1985. Bioeconomic modelling and fisheries management, John Wiley \& Sons, New York.

Clark C.W., 1990. Mathematical bioeconomics: the optimal management of renewable resources, John Wiley and Sons, New York.

Hannesson R., 1993. Bioeconomic analysis of fisheries, Fishing News Books: Blackwell Science, Oxford.

Jennings S., Kaiser M.J. \& Reynolds J.D., 2001. Marine fisheries ecology, Blackwell Science, Oxford.

Kar T. K. and Chaudhuri K. S., 2003. Regulation of a prey-predator fishery by taxation: a dynamic reaction model. Journal of Biological System, Vol. 11, No. 2, pp. 173-187.

Kar T. K. and Chaudhuri K. S., 2004. Harvesting in a two-prey one predator fishery: a bioeconomic model, ANZIAM J. Vol. 45, pp. 443-456.

Kar T. K., Misra S. and Mukhopadhyay B., 2006. A bioeconomic model of a ratio-dependent predator-prey system and optimal harvesting, J. Appl. Math. Comp., Vol. 22, No. 1/2, pp. 387-401.

Kar, T.K. and Matsuda H, 2008. A bioeconomic model of a single species fishery with marine reserve, Journal of Environmental Management, Vol. 86, No. 1, pp. 171-180.

Kar T. K. and Chakraborty K., 2009. Marine reserves and its consequences as a fisheries management tool, World Journal of Modelling and Simulation, Vol. 5, No. 2, pp. 83-95.

Kizner Z., 1997. Stability properties of discrete stock-production models, Sci. Mar., Vol. 61, No. 2, pp. 195-201.

Kronbak L. G., 2005. The dynamics of an open-access fishery: Baltic Sea Cod, Marine Resource Economics, Vol. 19, pp. $459-479$. 
Loehle C., 2006. Control theory and the management of ecosystems, Journal of Applied Ecology, Vol. 43, pp. 957-966.

Mikkelsen E., 2007. Aquaculture-Fisheries Interactions, Marine Resource Economics, Vol. 22, pp. 287-303.

Patra B., Maiti A. and Samanta G.P., 2009. Effect of time-delay on a ratio-dependent food chain model, Nonlinear Analysis:

Modelling and Control, Vol. 14, No. 2, pp. 199-216.

Pitcher T.J., Kalikoski D., Short K., Varkey D. and Pramoda G., 2009. An evaluation of progress in implementing ecosystembased management of fisheries in 33 countries, Marine Policy, Vol. 33, pp. 223- 232.

Pomeroy R., Nguyen K.A.T. and Thong H. X., 2009. Small-scale marine fisheries policy in Vietnam, Marine Policy, Vol. 33, pp. 419-428.

Thorpe A., Whitmarsh D., Ndomahina E., Baio A., Kemokai M., and Lebbie T., 2009. Fisheries and failing states: The case of Sierra Leone, Marine Policy, Vol. 33, pp. 393-400.

Wang L., Xu R. and Tian X., 2009. Global stability of a predator-prey model with stage structure for the Predator, World Journal of Modelling and Simulation, Vol. 5, No. 3, pp. 192-202.

Wieland R., 2007. Managing oyster harvests in Maryland's Chesapeake Bay, NOAA Chesapeake Bay Office, Non-native Oyster Research Program.

\section{Biographical notes}

Dr. T. K. Kar is an Associate Professor at the Department of Mathematics, Bengal Engineering and Science University, Shibpur, in India. His research interests include Dynamical systems, stability and bifurcation theory, population dynamics, mathematical modeling in ecology and epidemiology, management and conservation of fisheries, bioeconomic modeling of renewable resources. He wrote around 50 academic papers on those topics. He also supervised several students of master and doctor degree.

Kunal Chakraborty is a Lecturer at the Department of Mathematics, MCKV Institute of Engineering, Howrah, in India. He is currently doing his Ph.D. under the guidance of Dr. T. K. Kar in the Department of Mathematics, Bengal Engineering and Science University, Shibpur, India. His research topic is "Bio-economic modelling and development of solution techniques for the management and conservation of fisheries". He has obtained his post graduate degree in Mathematics from the University of Burdwan in 2006.

Received October 2009

Accepted November 2009

Final acceptance in revised form December 2009 